\title{
LA ESCRIBANÍA DEL CONCEJO DE TERUEL EN LA BAJA EDAD MEDIA: EVOLUCIÓN E INJERENCIA MONÁRQUICA
}

\author{
THE COURT SCRIBE OF THE COUNCIL OF TERUEL \\ DURING THE LATE MIDDLE AGES: \\ EVOLUTION AND ROYAL INTERFERENCE
}

\author{
Alejandro Ríos CONEJERO \\ Universidad Complutense de Madrid \\ arios04@ucm.es
}

Resumen: Los escribanos siempre han sido un engranaje imprescindible en la maquinaria de gobierno en cualquier época y circunstancia. A lo largo de este trabajo se analizará la figura del escribano del concejo de Teruel durante la Baja Edad Media. A la par, se estudiarán los diversos intentos por parte de la monarquía aragonesa de interferir en su designación, así como los enfrentamientos jurídicos que ello generó entre el municipio y la Corona.

Palabras clave: Teruel, Baja Edad Media, concejo, escribano, escribanía.
Abstract: Scribes have always been an important gear in the government machine in every age. Through these pages we will study the figure of the Turolean council's scribe during the Late Middle Ages. At the same time, we will analyze different attempts carried out by the Aragonese monarchy in order to meddle in its designation, and juridical confrontations held up between the town and the Crown.

Key words: Teruel, Late Middle Ages, town council, scribe, scribe's court. 


\section{Introducción}

La escritura, desde sus orígenes, ha sido un medio de control económico, social e ideológico con un papel decisivo en la evolución y fortalecimiento del poder (Lethonen, 2007: 15). Además de ser una herramienta de reproducción de los sistemas establecidos, merced a la capacidad de conservación de los elementos escritos frente a la transitoriedad de la oralidad. Es por esto que las clases dominantes de diversas y numerosas culturas se han servido de diferentes sistemas escriturarios para sostener su sistema y reproducirlo (Rodríguez, 1988: 11-12).

Durante la Baja Edad Media, las instituciones representantes de los diferentes grupos de poder - monarquía, Iglesia, nobleza y concejos- hicieron uso de la escritura para gestionar y administrar los territorios y colectivos humanos bajo su paraguas competencial. Gracias a ello consiguieron un mayor control en áreas como el gobierno, el sistema judicial o la fiscalidad. Pero, además, la escritura también sirvió a estas entidades para relacionarse entre sí, dejar constancia de sus actuaciones y conservar información a la que podían acceder más adelante (Camino, 2004: 97; Puñal, 2019: 143).

Consecuencia de este hecho es la eclosión documental vivida durante los últimos siglos de la Edad Media, cuyo reflejo se puede observar en la cantidad de documentación perteneciente a estas centurias que se conserva en los diferentes archivos. En concreto, la institución concejil objeto de este trabajo experimentó una creciente utilización de la escritura como instrumento de gestión, resultado de la complejidad del gobierno urbano y el desarrollo y consolidación de una administración más burocratizada.

La creciente necesidad de poner por escrito los diferentes actos y reuniones, pero también la supervisión y control de la producción escrita, trajo aparejada la aparición de la figura del escribano. Ya que, tal y como indicó David Torres (1982: 106) estos oficiales fueron imprescindibles para las tareas de gobierno en cualquier época y circunstancia. Profesionales de la escritura que quedaron insertos dentro del organigrama institucional concejil, encargados de la producción de la documentación elaborada por la administración municipal, la recepción de los escritos dirigidos a la misma y la custodia de todo el corpus documental generado (Ruiz, 2018: 201; Corral, 1987: 57-71).

No obstante, tal y como tendremos ocasión de analizar, la posesión efectiva del cargo de escribano del concejo no significaba el desempeño real del mismo. 
En muchos concejos hispánicos se trataba de una más de las magistraturas elegidas anualmente, por lo que tenía un carácter más honorífico remunerativo que una función en la administración. Este hecho obligó a instaurar la costumbre de nombrar lugartenientes, normalmente elegidos entre las filas del notariado urbano y que poseían los conocimientos técnicos necesarios para realizar el trabajo asignado (Conde-Francisco, 1989: 309-312; Pardo, 2000: 361).

Circunstancia que no obsta para que, tanto los escribanos como sus lugartenientes, gozaran de los amplios beneficios asociados a su puesto. No nos referimos únicamente a las gratificaciones económicas directas, sino al poder del que disponían gracias al acceso a información político-económica sensible, la cual se derivaba de su asistencia obligatoria a los actos del concejo y el consejo. Por otro lado, aunque penado por la ley, su posición les permitía desarrollar prácticas fraudulentas con el fin de beneficiar o perjudicar a determinados individuos o grupos sociales. Estos fraudes podían ir desde el falseamiento de libros de cuentas o actas concejiles, a retrasarse deliberadamente en la realización de copias y trasuntos, traspapelar o perder deliberadamente determinados documentos de los que eran custodios (Díez, 1998-1999: 312; Leva, 2009: 69).

Ahora bien, no solo se desprendían beneficios individuales, sino que determinados sectores poblacionales podían verse beneficiados de las actividades del escribano. Es el caso de las oligarquías urbanas que dominaban la escena político-social de los concejos, pues estas se servían de los conocimientos técnicos y del lenguaje jurídico-político de los escribas para desarrollar su discurso político y conformar una ideología común a todo el cuerpo social urbano (Barrio, 2011: 440-442).

En vistas de las ganancias directas e indirectas que conllevaba esta magistratura, no es de extrañar que los diferentes poderes con acceso a los concejos - monarquía, patriciado urbano y, en determinados casos, señores laicos o eclesiásticos - intentasen controlar este puesto. Dominio que, en la mayoría de ocasiones, no pasaba por el disfrute directo del cargo, sino que residía en la potestad de abrir o cerrar su acceso a terceros (Jara, 2001: 250-252; Puñal, 2019: 131-132).

El objetivo de este trabajo es analizar la escribanía del concejo de Teruel desde sus orígenes a finales del siglo XII hasta los inicios de la modernidad. Ya que, si bien varios autores hablan de esta figura en diversas publicaciones, el conocimiento que tenemos de ella es todavía sesgado, incluso nulo en deter- 
minadas épocas. En este sentido, tanto Antonio Gargallo (1996: 760-764) como Vidal Muñoz (2007: 184-185) explican el origen, funciones y remuneración de este magistrado local al analizar el concejo turolense durante sus primeros siglos de existencia. Por otro lado, José Luis Castán (2008: 50; 2009: 121), José Manuel Latorre e Isabel Pérez (2006: 31) hicieron lo propio para fechas posteriores, centrándose el primero en las funciones judiciales del escribano durante el siglo XVI, mientras que los segundos examinaron esta institución concejil en el siglo XVII.

Pese a la labor de estos investigadores, este oficio de la administración medieval turolense adolece de estudios en profundidad como los realizados sobre otros concejos peninsulares. Pero, sobre todo, nadie ha prestado atención a los momentos finales del medievo, de vital importancia para entender su evolución desde sus orígenes hasta llegar a ser el escribano que se define en la suma de fueros de Juan del Pastor (Castán, 2010). Máxime cuando a finales del siglo XIV y comienzos del XV el concejo turolense promulgó varias ordenanzas sobre la labor del escribano de la sala del concejo y de la corte del juez y alcaldes de la ciudad, así como de los notarios que le auxiliaban. Estatutos que, tal y como indicaron Miguel Ángel Ladero e Isabel Galán (1982: 225227), tienen un gran valor a la hora de estudiar situaciones locales específicas, aspectos de la vida municipal y líneas evolutivas.

Por todo ello, en este trabajo se tratará de explicar la figura del escribano del concejo de Teruel, su origen y su evolución durante la Baja Edad Media, a través del fuero, diversos privilegios reales y ordenanzas concejiles. Asimismo, en un segundo apartado nos centraremos en los distintos intentos de la monarquía aragonesa por interferir en este cargo e imponer a la persona que lo ocupara, con los consiguientes enfrentamientos judiciales que ello conllevó.

\section{La escribanía del concejo de Teruel}

A diferencia de las ciudades y villas de la zona septentrional de la península Ibérica, donde gran parte de las instituciones fueron resultado de la evolución de otras preexistentes, en la zona meridional muchos organismos fueron creados por el monarca, o el señor del lugar, en el momento de la población del territorio recién conquistado.

En este sentido, el origen del escribano del concejo turolense parece remontarse a los inicios de la institución concejil establecida por Alfonso II a 
finales del siglo XII. Este oficial vino a cubrir las necesidades del nuevo gobierno de la villa, dar testimonio de las reuniones del conjunto de los vecinos y elaborar la documentación que se precisase en las tareas administrativas. Situación que también puede apreciarse en diversas poblaciones del sur castellano, como Jerez de la Frontera o Sevilla (Ruiz, 2018: 195-196).

Si bien estas instituciones son de nueva planta, ello no significa que fueran creadas desde cero, sino que siguieron el modelo previo de otros municipios. Parece que el caso turolense sigue el arquetipo estipulado en el fuero de Daroca, en donde ya se describe la existencia de un escribano entre las principales magistraturas de la villa. El código legal darocense también explica la forma en la que había de ser elegido; al igual que el resto de la corporación municipal, era constituido a voluntad y arbitrio del concejo el octavo día de Pascua, teniendo una duración anual. ${ }^{1}$ No obstante, la parquedad con la que esta compilación foral describe y regula las funciones de este cargo, característica compartida por la mayoría de fueros extensos ibéricos coetáneos, podría ser un indicativo de la escasa necesidad de su intervención durante esta primera etapa, ya que únicamente actuarían de forma esporádica (García, 2015: 286).

El sistema de elección implementado en la villa de Teruel y descrito en su fuero es muy similar. El martes siguiente al domingo de Pascua de Resurrección se debía elegir a los magistrados concejiles, quienes permanecerían en su cargo durante un año. Periodicidad que podía aumentarse en caso de que el concejo en pleno así lo pidiera, ${ }^{2}$ aunque no conocemos ningún caso en el que esta prórroga se llevara a cabo. La anualidad del cargo de escribano parece ser común a muchos concejos, tanto aragoneses como castellanos. No obstante, habida cuenta de los problemas que acarreaba el constante cambio de profesionales, durante los siglos posteriores este oficio tendió a convertirse en vitalicio en gran número de municipios de la corona aragonesa, como Barcelona, Valencia, Zaragoza o Huesca (Iranzo, 2004: 441).

Con respecto a los requisitos que se exigían a los aspirantes, el código legal turolense estipulaba que cualquier persona que quisiera presentar su candidatura a un puesto concejil debía de tener una casa en la villa y habitar en

1 Fuero de Daroca, §45: Iudex, alcaldes, scriba, almotaçaf, ianitor ville, andadores, saion, defensarius, uinitiores et ceteri huismodi mittentur voluntate et arbitrio concilii octavo die sancte Pasche et mutentur annuatim eodem die. (Agudo, 1992: 51).

2 Fuero de Teruel, $\S 60$ (Castañé, 1989: 87-89). 
ella, amén de un caballo valorado en 200 sueldos jaqueses. ${ }^{3}$ Pero, además, para el cargo de escribano se requería poseer conocimientos técnicos apropiados para desarrollar su cometido: saber hacer cuentas, leer, escribir y poder comprender e interpretar el fuero y las sentencias dadas en la corte del juez. ${ }^{4}$ A pesar de ello, no parece ser que en Teruel se recurriera a notarios públicos para este menester, tal y como se ha documentado en otras urbes de la península Ibérica (Ruiz, 2018: 195; Gomariz, 2003-2004: 47).

En cuanto a sus labores, recaía sobre él toda la gestión burocrático-administrativa del concejo. En primer lugar, debía de dar fe y testimonio de todo lo acordado en los diferentes órganos gubernativos de la urbe, para ello confeccionaba las actas de las reuniones ordinarias y extraordinarias, expedía los documentos requeridos y los validaba con el sello del concejo. ${ }^{5}$ Simultáneamente, ayudaba a otros oficiales en tareas fiscales, como realizar el padrón de la pecha o llevar las cuentas de este y otros tributos; ${ }^{6}$ también era el encargado de llevar la contabilidad del concejo y de los oficiales, con el fin de evitar que estos realizaran algún fraude.

A todo ello se sumaban las tareas que el escribano desarrollaba en el ámbito jurídico. De acuerdo a su labor como auxiliar del juez y los alcaldes, el escribano debía estar presente en los juicios que estos llevaban a cabo y poner por escrito los veredictos emitidos. Este quehacer tenía especial relevancia en las sentencias reales o concejiles dadas en las causas apeladas ante ellos, puesto que pasaban a engrosar el liber iudiciorum y se incluían en la compilación legal turolense. Así mismo, al estar versado en el fuero y su interpretación, ejercía junto con el juez y los alcaldes como tribunal de apelación en segunda instancia. Ante esta audiencia podían reclamar quienes no estuvieran acordes con las sentencias emitidas en primera instancia por el juez y los alcaldes, en donde el escribano, como garante de la correcta interpretación del fuero, se aseguraba que la sentencia previa no incurría en contrafuero (Gargallo, 1996: 762-763; Castán, 2009: 50, 61).

\footnotetext{
Fuero de Teruel, §61 (Castañé, 1989: 89).

Fuero de Teruel, $\S 85$ (Castañé, 1989: 107).

Fuero de Teruel, $\$ 84$ (Castañé, 1989: 107).

A pesar de lo indicado en el fuero, donde se estipula que eran el escribano y los jurados de las aldeas quienes redactaban este censo fiscal, Antonio Gargallo apunta que en las ordenanzas que Pedro II instauró en 1208 se especifica que esta tarea recaía el juez de la villa y una comisión de jurados (Gargallo, 1996: 747). No obstante, a tenor de que el escribano ejercía como auxiliar y segundo del juez no sería extraño que el principal magistrado delegase en el escribano, costumbre que acabó cristalizando en el código legal.
} 
Como contraprestación a los servicios realizados, el concejo debía entregar al escribano un sueldo anual de 100 sueldos jaqueses y tenía derecho a una parte especial de los botines de guerra, concretamente un musulmán cautivo de cada expedición llevada a cabo por la hueste del concejo. ${ }^{7}$ Seguramente este estipendio fuera un sueldo base, al cual se sumaría una comisión de las tasas que esta escribanía cobraba a los particulares por la expedición de copias y trasuntos. Pero, a pesar de que conocemos los gravámenes impuestos a algunos de estos documentos (Gargallo, 2005: 376-382), carecemos de información que nos ilustre sobre el porcentaje que sería para el escribano y el que iría a engrosar las arcas concejiles.

Acabado el año de mandato, este magistrado debía presentar ante sus convecinos sus cuentas, con el fin de evitar irregularidades o fraudes. No obstante, su simple juramento debía ser admitido como prueba suficiente de la fiabilidad y buena fe del balance presentado. ${ }^{8}$ Aun con todo, durante los seis meses subsiguientes a su cese todavía seguía siendo responsable de su gestión, por lo que podía ser procesado si se detectaba algún delito. Entre las transgresiones más graves se contaban el falseamiento de datos en los libros de cuentas o textos legales y la realización de falsificaciones. ${ }^{9}$ En caso de ser hallado culpable, debía de pagar el doble del daño ocasionado por el fraude, siempre que este fuera menos de 100 sueldos jaqueses, mientras que en caso de ser superior debía resarcir el doble del daño más 100 maravedíes que irían destinados a reparar las fortificaciones de la urbe. Si el encausado no podía abonar la multa, la legislación turolense incluía castigos corporales como la amputación del dedo pulgar, lo que se traducía en la incapacitación permanente para realizar su trabajo. ${ }^{10}$

La primera persona en ocupar este cargo de la que tenemos noticia es Pedro, diácono de la iglesia de San Salvador, en 1200 (Gargallo, 1996: 760). Tal y como indica Isabel García (2015: 290), no es extraño encontrar a religiosos ejerciendo de escribanos hasta mediados de la decimotercera centuria, a pesar de la reticencia generalizada a que miembros del estamento clerical ocupasen

7 Fuero de Teruel, $\S 86$ (Castañé, 1989: 107-109).

8 Fuero de Teruel, \$86 (Castañé, 1989: 109).

9 A pesar de que no contamos con ejemplos concretos, sirva como muestra un caso documentado en Huesca por María Teresa Iranzo (2004: 247): Fortún de Antaños fue acusado en 1305 de haber recibido un soborno de 40 sueldos jaqueses a cambio de incluir el nombre de un vecino en el libro de los francos, documento en el cual figuraban aquellas personas exentas de participar en las contribuciones vecinales.

10 Fuero de Teruel, §87-88 (Castañé, 1989: 107-109). 
estos cargos,${ }^{11}$ recelo que se tradujo en una prohibición directa en los fueros de Aragón recopilados en 1247 (Falcón, 1997: 135). Este veto también era común en la Corona de Castilla, donde se exigía a los escribanos la pertenencia al estado laico, si bien había abundantes excepciones a la norma e infracciones (Rábade, 1991: 267-268). No obstante, dado que en esas fechas Teruel hacía una veintena de años que había sido fundada, es más que posible que ante la ausencia de gente letrada entre las filas de los caballeros villanos se recurriera a clérigos que supieran leer y escribir. Según Vidal Muñoz, hasta mediados del siglo XIII no se tiene noticia de escribanos laicos; los primeros localizados son, concretamente, Ferrant de Sevilla y D. Bernabé en 1266 (Muñoz, 2007: 185), si bien podrían haber existido otros anteriores de los cuales no se ha conservado información.

Asimismo, aunque en la legislación turolense no se regulara sobre el lugarteniente del escribano, se trataba de una figura muy extendida en las escribanías de la época. La misión de estos auxiliares era ayudar al escribano en sus diversas tareas, así como sustituirlo en momentos puntuales. Sin embargo, en muchas ocasiones estas delegaciones se convirtieron en algo habitual y constante, lo que permitió que la magistratura concejil originaria se transformara en un cargo honorífico disociado del trabajo real de amanuense, mientras que los lugartenientes pasaron a ser quienes realmente desempeñaban las funciones del cargo. Aunque Antonio Gargallo (1996: 763) ya detectó la existencia de lugartenientes sustituyendo al escribano del concejo, no conocemos que esta eventualidad estuviera regulada hasta 1396, cuando el gobierno municipal promulgó una serie de ordenanzas relativas al mismo, tal y como veremos más adelante. ${ }^{12}$

Durante el siglo XIII el oficio municipal objeto de este estudio evolucionó y absorbió competencias que en origen le eran ajenas. Aunque la falta de documentación nos impide precisar el proceso concreto, sí sabemos que afectaron principalmente a dos ámbitos, el fiscal y el judicial. En cuanto al primero de ellos, las atribuciones del escribano del concejo relacionadas con la recaudación de impuestos y tributos aumentaron considerablemente. Si en origen su labor era únicamente la redacción del censo fiscal, a lo largo del Doscientos

11 Jaime II, en una carta dirigida a la ciudad y aldeas de Teruel, explicaba que la causa de esta animadversión era que los clérigos se refugiaban en la justicia eclesiástica, consiguiendo evitar ser procesados por la justicia civil en procesos derivados de su actuación como escribas (Conde-Francisco, 1989: 303).

12 Archivo Histórico Provincial de Teruel (en adelante AHPTE), Concejo, Caja Azul, carpeta 5, docs. 124 y 125 . 
sus facultades recaudatorias se fueron asimilando a las del juez, al menos en el cobro de la pecha forera y diversos servicios que la villa y las aldeas pagaban a la Corona. Tareas que en origen parece realizar por delegación del juez, pero cuya adición a las competencias del escribano quedó institucionalizada desde 1325 con la sentencia de Valencia (Gargallo, 1996: 747 y 762; Muñoz, 2007: 185).

Con respecto al ámbito jurisdiccional, es donde más aumentaron sus prerrogativas. Además de continuar como auxiliar de los tribunales del juez y los alcaldes, su labor como custodio e intérprete del fuero hicieron que su figura adquiriera mayor importancia en las apelaciones que se hacían a las sentencias de estos magistrados. En este sentido, el escribano desplazó al juez y a los alcaldes del tribunal de segunda instancia conformado por todos ellos, lo que acabó resultando en un órgano unipersonal: el juez padrón o iudex apellationum patroni. Denominación que le sobrevino por su labor como intérprete y garante de los fueros, también llamados 'libro padrón' (Castán, 2009: 62). Se trataba de un tribunal de apelación que velaba porque las sentencias dadas en primera instancia fueran acordes al fuero. Sin embargo, no tenemos un conocimiento conciso sobre su funcionamiento hasta mediados del siglo XV.

A finales de la decimocuarta centuria, concretamente el 12 de marzo de 1396, los miembros del concejo reunidos en la puerta de la iglesia de Santa María de Mediavilla decidieron regular el funcionamiento de la escribanía de la sala del concejo, así como la escribanía de la corte del juez, los alcaldes y el juez padrón..$^{13} \mathrm{~A}$ tal efecto, se debían elaborar unas ordinaciones que legislaran sobre la elección de estos oficiales, sus funciones y salario. Estas debían seguir unas las líneas generales preacordadas: ambos notarios ejercerían por el tiempo que sus superiores considerasen necesario y su labor sería poner por escrito todas las decisiones tomadas por el concejo y los tribunales de justicia respectivamente, así como recibir y despachar toda la documentación que desde estos órganos se les requiriera. Simultáneamente, se debía designar a un notario para ocupar la escribanía de la sala y otros dos para la corte del juez.

La tarea reformadora recayó sobre los regidores más un grupo de seis personas: dos representantes de los caballeros y mano mayor - Pedro Sánchez Muñoz y Francisco Martínez de Cuevas-, dos diputados de las manos media

13 Si bien no se ha conservado documentación directa de esta asamblea, en el preámbulo de las citadas ordinaciones se insertó copia de lo dispuesto en ella (AHPTE, Concejo, Caja Azul, carpeta 5, docs. 124 y 125). 
y menor - Nicolás Palaciano y Gil Fillol— y Sancho Martínez de Xiarch y Fortuñón de Sesa como representantes de la compañía de los notarios. ${ }^{14} \mathrm{La}$ elección directa de representantes del colectivo de notarios junto a los comisionados por las manos mayor, mediana y menor, si bien desacostumbrada en estos menesteres, no es de extrañar si tenemos en cuenta que las ordinaciones que se iban a promulgar les afectaban directamente.

Apenas quince días después, el 3 de abril, esta comisión presentó ante el concejo la normativa que había acordado, la cual fue leída, aprobada y publicada. Asimismo, fueron presentados los candidatos para ocupar las citadas notarías, Rodrigo Ruiz de Mesa y Francisco Galve, hijo de Gil Galve, para la escribanía del juez y Pedro López de Maluenda para la escribanía de la sala del concejo. Todos ellos fueron ratificados, por lo que aceptaron el oficio y juraron cumplir las ordinaciones recién instauradas, amén de obligar sus bienes y personas como garantía de su buen hacer.

El reglamento que pasaba a regir la escribanía de la sala del concejo ${ }^{15}$ hacía referencia a dos oficiales: el escribano del concejo, también llamado escribano anual, y el notario que le auxiliaba en su tarea. Del primero se especifica su elección cada martes de Pascua, al igual que la del resto de magistrados del concejo, y el sueldo de 100 sueldos jaqueses que dictaba el fuero, así como otros 50 sueldos jaqueses que era costumbre entregarle para costear la cera y el papel que debía utilizar. Además, se confirmaba su derecho a percibir una tasa por cada documento que el concejo o alguno de los oficiales mandara ratificar con el sello de la ciudad, del que era custodio. A este salario decidieron sumar un estipendio de 500 sueldos jaqueses anuales, a cobrar en la vigilia del día de Navidad, en conpensacion et remuneracion de algunas otras cosas quel dito scrivano anyal aver debe dela dita ciudat. ${ }^{16}$

14 A diferencia de otras cofradías mejor conocidas, como la de los labradores, la de tejedores o la de caballeros bajo la advocación de San Jorge, poco o nada sabemos de la que agrupaba a los notarios turolenses. Más estudiadas han sido, sin embargo, las cofradías de notarios de Zaragoza y Huesca. El origen de ambas se remonta a 1328, año en el que fueron creadas y el monarca Alfonso IV confirmó sus ordenanzas. Estas dos asociaciones de notarios se hallaban bajo la advocación de san Luis, obispo y confesor, y tenían un fin religioso-benéfico-asistencial (Falcón, 1997: 137-139).

15 AHPTE, Concejo, Caja Azul, carpeta 5, doc. 124.

16 Entre la documentación fiscal conservada en el Archivo Histórico Provincial de Teruel se conservan varios legajos que atestiguan estos pagos. Basten como ejemplo las tres órdenes de pago emitidas por los regidores del concejo a favor de Juan de Villaspesa, juez padrón, el 21 de diciembre de 1422: la primera por valor de 50 sueldos jaqueses que la ciudat haver devia, juxta la ordinacion dela escrivania dela dita sala, por la cera de las letras (AHPTE, caja 32, doc. 52), la segunda de 500 sueldos jaqueses por su trabajo en la escribanía (AHPTE, caja 33, doc. 2) y un último pago de 100 sueldos jaqueses que 
Por lo que se refiere al notario que se ocuparía de facto de esta escribanía, se establecía su elección por el consejo, organismo que también decidiría el tiempo que duraría su servicio. La persona elegida no podía delegar en terceros, sino que debía realizar el trabajo personalmente, lo cual lo obligaba a residir en la ciudad mientras ocupara este cargo. En el caso de que el notario seleccionado no quisiera ejercer el oficio, o no lo ejerciera en persona de forma injustificada, incurría en una pena de 100 florines de oro de Aragón, cantidad que se repartía en tres partes: una para la reina, otra para el juez o alcalde que llevara el caso en los tribunales y la última para las arcas de la ciudad. ${ }^{17}$

Sus funciones se resumían en tomar nota de los mandamientos y ordinaciones promulgadas por el consejo y el concejo, así como redactar todos los contratos de compra-venta o arrendamientos, y las cartas de préstamo, comandas o censales realizados en nombre de la ciudad. Asimismo, debía registrar todos los albaranes, ápocas y recibos emitidos por la administración municipal. Por todo ello recibía del escribano anual una paga de 50 sueldos jaqueses al año, quien también debía suministrarle el papel que precisase. A dicho salario se sumaba una cantidad no especificada por cada documento que los regidores o procuradores le pidieran hacer, ${ }^{18}$ si bien algunos albaranes nos hablan de la percepción de cantidades nada desdeñables. Basten como ejemplo los 609 sueldos jaqueses y 6 dineros que Pedro Sánchez de Valdeconejos, notario de la sala, recibió de los regidores por realizar diversas escrituras en 1423; o los 1290 sueldos jaqueses que recibió este mismo notario por un trabajo similar en $1427 .{ }^{19}$

Como colofón, los regidores y los seis diputados ordenaron la construcción de un archivo en las casas del consejo, con el fin de guardar los registros elaborados por este notario y los documentos relevantes para la ciudad. ${ }^{20} \mathrm{Cir}-$

de la dita ciudat haver devia de senderias juxta los capitoles del regimiento de aquella (AHPTE, caja 33, doc. 3).

17 [El notario] esleydo sea tenido et deva acceptar et acepte el dito oficio toda ora que sea esleydo [...] por cadascuna vegada quel dito oficio recusara o no querra acceptar ni personalment servir segunt dito es seyendo enla dita ciudat concurra en pena et por nombre de pena de cient florines d'oro comunes d'Aragon. AHPTE, Concejo, Caja Azul, carpeta 5, doc. 124.

18 Si esdevendra o acayecera los ditos regidores o procuradores dela dita ciudat fazer et atorgar alguna carta o contracto, el qual sera en scierta et acostumbrada tachacion, quel dito notario sea tenido recebir et reciba por su salario et paga aquello que por los regidores qui la ora seran dela dita ciudat les sera tachado et mandado dar et nomas. AHPTE, Concejo, Caja Azul, carpeta 5, doc. 124.

19 AHPTE, Concejo, caja 33, docs. 18 y 22 respectivamente.

20 Item statuymos encara et hordenamos que por la dita ciudat o procurador daquella qui por tiempo sera sea fecho et se faga enlas casas del consello dela dita ciudat, alli et en aquel lugar do alos regidores 
cunstancia que, si bien se empieza a detectar desde mediados del siglo XIII en ciudades del norte de Europa, no es común en la península Ibérica hasta finales del siglo XIV o principios del XV (García, 2015: 288-289). No sabemos si con anterioridad a este decreto ya existía un lugar dedicado a este fin o si el escribano del concejo debía custodiar toda esta documentación en su domicilio pero, a tenor de que los tribunales de justicia se situaban en la casa particular de quien ocupara ese año la magistratura, nos inclinamos por la segunda opción, con los problemas que ello acarreaba. ${ }^{21}$

La creación de un lugar específico para la custodia de los diversos fondos documentales que conformaban el archivo concejil denota la importancia que se concedía a estos legajos. Elemento de prestigio, pero que también cumplía unas funciones básicas: arsenal jurídico para defender sus privilegios y poder en caso de ser cuestionados, servía a la oligarquía para administrar y gobernar la ciudad y las aldeas a su cargo y, gracias a él, se mantenía la memoria e identidad de la ciudad. Idea que se incardina en la aseveración de Jacques Le Goff (1991: 134):

La memoria ha constituido un hito importante en la lucha por el poder conducida por las fuerzas sociales. Apoderarse de la memoria y del olvido es una de las máximas preocupaciones de los individuos que han dominado y dominan las sociedades históricas.

Durante esta misma reunión, los regidores y diputados elegidos en representación de los tres colectivos también presentaron las ordinaciones que habían acordado sobre los notarios que regirían la escribanía de la corte del juez, alcaldes y juez padrón. ${ }^{22}$ En este caso era la ciudad, a través de los regidores, quien seleccionaba a dos notarios para este puesto durante el tiempo que se estimase oportuno. Oficio que los incapacitaba para tomar parte en los juicios o asesorar a cualquiera de las partes litigantes, bajo pena de 150 maravedíes de oro. Asimismo, como ocurría en el caso anterior, la no aceptación del cargo

qui agora son o por tiempo seran sera visto mas expedient, es asaber hun archiu enel qual sean puestos et sten los registros del dito notario et todas et quales quiere scripturas otras fazederas o recebideras assin porel dito notario como porel scribano anyal et que sera por suert fazientes et tocantes o si quiere concernientes o que fara et tocaran et concerteran al conseio et conceio et interes dela dita ciudat et interes de aquella et de aquellos. AHPTE, Concejo, Caja Azul, carpeta 5, doc. 124.

21 Los continuos traspasos de la documentación podían conllevar pérdidas, además de ser el momento idóneo para que escribanos corruptos pudieran traspapelar registros en su propio beneficio. A lo que se sumaba la desidia de algunos escribanos por custodiar el archivo (Rábade, 1992: 221-223).

22 AHPTE, Concejo, Caja Azul, carpeta 5, doc. 125. 
conllevaba una sanción de 50 maravedíes de oro. La cuantía de ambas multas se repartía a partes iguales entre el juez y las arcas municipales.

Por lo que se refiere a sus obligaciones, estos amanuenses debían redactar todos los documentos necesarios para el desarrollo de los procesos y juicios, tanto de instancia como a petición de las partes. ${ }^{23}$ Más aún, en estas ordinaciones se especificaba la forma en que se debían hacer los originales y copias:

[...] los ditos dos notarios sean tenidos poner, escrevir et continuar en cadascuna pieta o pagina de processo original et coppias quales quiere por via et manera de processo fetos et dados, es a saber dizeocho parts de buena continuacion.

No es de extrañar esta regulación si tenemos en cuenta que, al contrario que los notarios del concejo, no disponían de un salario fijo, sino que percibían una cantidad por cada documento expedido, a razón de 6 dineros cada página original signada y 4 por las copias signadas. Al mismo tiempo, también se especificaban diferentes cobros por servicios especiales que debían llevar a cabo estos oficiales, tales como requisitorias de prisión, acompañar al juez o alcaldes fuera de la ciudad o realización de inventarios de bienes entre otros.

A pesar de que no tenemos forma de poder llegar a conocer con exactitud las cuantías que podían ganar estos dos notarios, el puesto debía ser lucrativo ya que no sólo los de la urbe acudían a estos tribunales, sino que los habitantes de las aproximadamente setenta aldeas dependientes de Teruel también debían acudir a ellos en busca de justicia. La dependencia jurisdiccional de estos núcleos rurales, matizada por la sentencia de Escorihuela de 1277 a los pleitos de cuantía mayor a 5 sueldos jaqueses, perduró hasta el siglo XV, cuando Alfonso V

23 De entre la documentación emanada de la corte del juez de Teruel, las unidades documentales más interesantes posiblemente sean los manuales de corte, puesto que aportan información muy variada de la vida del municipio y la sociedad que en él vive. En estos libros el escribano anotaba todos los pleitos que eran llevados ante el tribunal, indicando el día en que se celebraba el juicio, las partes implicadas, la causa y la sentencia. Trágicamente solo tres ejemplares han llegado hasta nuestros días. El primero de ellos, custodiado en el Archivo Histórico de Teruel, contiene los litigios resueltos ante la corte del juez Pascual Benedicto entre el 10 de enero y el 31 de marzo de 1431 (AHPTE, Concejo, caja 22, doc. 1). Los otros dos, en cambio, se hallan en la sección de Varia del Archivo de la Corona de Aragón, procedentes de una compra realizada por esta institución al Sr. Pérez Uriz en 1974. Se trata de los libros de corte de los jueces García Sánchez de Campos (ACA, Diversos, Varia 24, vol. 16) y Pedro Martínez de Marcilla (ACA, Diversos, Varia 24, vol. 17), fechados en 1411 y 1434 respectivamente. Como ejemplo de la información contenida en esta tipología documental y su utilidad para el trabajo del historiador remitimos a los trabajos de Joaquín Aparici Martí sobre el Libro de la escribanía de don Federico de Aragón, conde de Luna (Aparici, 2011a; Aparici, 2011b; Aparici, 2013) 
y luego Juan II permitieron a las aldeas mayores cotas de libertad (Caruana, 1971: 246-248, 299). La riqueza devengada de la labor de esta escribanía también explica el arancel que debían abonar los notarios que la ocupaban. En este sentido debían pagar al juez y al juez padrón de cada año 500 sueldos jaqueses y otros 100 sueldos jaqueses respectivamente, en sustentacion o ayuda de su oficio. Ambos pagos se hacían fraccionados, entregando una primera mitad en la vigilia del día de Navidad y una segunda el día de Carnestolendas. ${ }^{24}$

La existencia de estos pagos periódicos nos puede hacer pensar que la elección de los notarios se trataba en realidad de un arrendamiento; sin embargo, la última cláusula del documento explica estos pagos. En ella se estipula otra retribución de 150 sueldos jaqueses anuales para el juez, si bien en este caso el pagador es la ciudad. La justificación aportada para este desembolso es que los jueces cobraban entre 650 y 700 sueldos jaqueses de la citada escribanía, dinero que dejaban de percibir con la entrada en vigor de la nueva normativa. A través de la suma de las cantidades que le debían entregar los notarios y la ciudad, los legisladores pretendían compensar de esta pérdida a los futuros magistrados..$^{25}$

De estas dos ordinaciones se infieren una importante serie de cambios con respecto a la etapa previa. En primer lugar, se puede observar una serie de medidas tendentes a la profesionalización de las escribanías dependientes del concejo, tales como dejar el trabajo efectivo de estas oficinas en manos de profesionales acreditados de la escritura elegidos por los regidores. También se buscaba que estos notarios ocupasen el cargo por periodos más largos que el año electoral, lo que aportaba continuación a la labor que desarrollaban. Esto no significa la desaparición de la magistratura concejil elegida anualmente, pues el escribano del concejo seguía siendo el cabeza de esta escribanía, el principal fedatario de la urbe y custodio del sello de la ciudad; además de tener amplias funciones en el ámbito judicial como juez padrón.

24 Se trata de cantidades cercanas a las que se venían pagando por el arrendamiento de instituciones de similar naturaleza. Baste como muestra el pago de 3.500 sueldos jaqueses que en 1354 hicieron Antoni Sanxo y Bartolomeu de Batea por poseer durante siete años la escribanía del justicia de Morella y su quincena de aldeas (Archivo Notarial de Morella, sig. 12, f. 55v. Protocolo de Domingo de la Guerola).

25 Como los jueces passados et encara a present ayan havido et costumbrado aver dela scrivania la qual es cosa propria et patrimonio de judez et su oficio encadaun anyo de seyscientos cinquanta o setecientos solidos no sea intencion delos ditos regidores et diputados prejudicar al dito judez por tanto ordenan et asientan quela dita ciudat sea tenida dar en pagar et de et pague a cadascuno delos juets esdevenidos et successores d'aqueste cient et cinquanta solidos. AHPTE, Concejo, Caja Azul, carpeta 5 , doc. 125 . 
Asimismo, al menos desde finales de la decimocuarta centuria, hay una separación efectiva de la escribanía de la sala del concejo de la escribanía dedicada a los tribunales de justicia. Mientras que para la referida al concejo esto no parece acarrear grandes cambios, la relativa al poder judicial se disoció del juez y juez padrón, quienes no solo perdieron las rentas que extraían de ella sino también la capacidad de nombrar a los notarios a favor del concejo, si bien ambos cargos fueron resarcidos económicamente por la enajenación.

Entrado ya el siglo XV, y aprovechando la celebración de Cortes en Teruel en 1429, los turolenses elevaron una queja Alfonso V acerca de las injusticias que se estaban cometiendo en tribunales de justicia de la ciudad. Por ello suplicaron al soberano que aprobase una serie de medidas en contra de la dilatación de los pleitos y subterfugios de dudosa legalidad que llevaban a cabo algunos litigantes, o aún miembros del aparato de justicia. El monarca aceptó la petición y confirmó las nuevas disposiciones que se añadirían al fuero, catorce ítems que modificaban la forma de proceder de los magistrados judiciales y buscaban agilizar los litigios.

Uno de estos preceptos explicitaba la forma en que debía intervenir el juez padrón en su función como tribunal de apelación. Se recordaba que disponía de un plazo máximo de ocho días para resolver en las cuestiones interlocutorias. Igualmente se dictaminaba que este no establecería un nuevo juicio, sino que examinaría los actos llevados a cabo por los órganos judiciales de primera y segunda instancia, el juez y el llamado «tribunal del viernes». También se decretaba una multa de 10 maravedíes en caso de que obrase de forma contraria a lo establecido, cantidad que se entregaría a la parte por la que fue llevada la interlocutoria (Agudo et al., 2007: 356). ${ }^{26}$

Hay que señalar, además, dos pasajes de estas disposiciones que afectaban a los oficiales de la escribanía de la corte de justicia. En el primero de ellos se establecía que en las causas de cuantías mayores que 60 sueldos jaqueses, los notarios debían tomar notas del proceso íntegro y dar una copia a cada una de las partes implicadas, por las que debía pagar un dinero y otros dos acabada la causa. En caso de que los litigantes requiriesen más copias, debían pagarlas según se había acostumbrado. Mientras que en el segundo ítem se determina-

26 A pesar de que en el texto original en latín se utiliza la expresión iudex patroni, las autoras de este trabajo sobre las adiciones realizadas al fuero de Teruel lo traducen como «juez del defensor». No obstante, atendiendo al vocablo latino, no cabe duda de que esta normativa se refiere a este magistrado. 
ba que, cada vez que hubiera un cambio de oficiales de justicia, ${ }^{27}$ los escribanos dispondrían de un plazo de veinte días para entregar toda la documentación generada en los pleitos en los que hubieran actuado (Agudo et al, 2007: 339-340 y 357).

Durante la década siguiente, concretamente en 1439, tuvo lugar la última reforma de la que tenemos conocimiento en la Edad Media sobre la figura del juez padrón. En esta ocasión parece que fue por iniciativa de los regidores de la ciudad, quienes decidieron entregar una gratificación de 50 sueldos jaqueses anuales a quien ocupara el cargo de escribano anual/juez padrón, en concepto de «cobranza de letras y albaranes» (Muñoz, 2007: 217).

Todos los cambios, modificaciones y añadidos, tuvieran su origen en la monarquía o en los órganos de gobierno municipales, fueron recogidos por Juan Pastor, quien los incluyó en su Suma de fueros de las ciudades de Santa María de Albarracín y de Teruel, de las comunidades de aldeas de dichas ciudades y de la villa de Mosqueruela, y de otras villas convecinas, compendio redactado durante el primer tercio del siglo XVI. ${ }^{28}$ Esta compilación, que estuvo en vigor hasta su derogación por Felipe II en 1598, vino a cristalizar una institución medieval que sobrevivió al propio corpus legal y que, con pequeñas modificaciones realizadas en la segunda mitad del siglo XVII (Latorre y Pérez, 2006: 12-35), perduró durante gran parte de la modernidad.

\section{La escribanía turolense y el intervencionismo regio}

Tal y como hemos visto al analizar la evolución de esta institución y las normativas que la regían, este organismo municipal se encontraba en manos del concejo turolense desde la fundación de la urbe hasta la abolición de sus fueros a finales del Quinientos. No obstante, a lo largo de todo el periodo medieval, los sucesivos monarcas aragoneses trataron de injerirse en el nombramiento del escribano o de los notarios que le auxiliaban.

El primer soberano en interferir fue Pedro III, quien debido al clima de violencia desatado en Teruel durante la década de los ochenta del siglo XIII no dudó

Recordemos que estas sustituciones eran bastante habituales puesto que si no ocurría nada extraño los cargos del concejo, entre los cuales se hallaban el juez y alcaldes, tenían una duración anual.

28 En concreto estas normativas aparecen en los apartados §98-103, 257, 279 y 288 (Castán, 2010: 59-64, $140,154,159)$. 
en suspender los cargos concejiles y sustituirlos por oficiales nombrados directamente por él. Al mismo tiempo, ordenó realizar una inspección acerca de la elección de los miembros del concejo, en torno a la que sospechaba que podían existir irregularidades, de lo que resultó el procesamiento de medio centenar de oligarcas locales (Ríos, 2016a: 286-287). Ante esta enajenación, los turolenses interpusieron una demanda contra el procurador fiscal del rey, en la cual requerían que el monarca devolviese al concejo la capacidad de designar a sus propios magistrados y que restituyese la escribanía del concejo al mismo. ${ }^{29}$ Pedro III atendió a la petición y devolvió estos oficios a los turolenses el 3 de octubre de 1283, al mismo tiempo que él y su primogénito Alfonso confirmaban los fueros de Teruel. De lo que resultó que fue tornada la dita scrivania a la dita ciudat e reconoscido aquella seyer propria de la dita ciudat. ${ }^{30}$

Sin embargo, a pesar de la reposición de las magistraturas municipales, la violencia desatada en Teruel por las luchas de bandos y por el enfrentamiento entre la urbe y las aldeas hicieron que los sucesivos monarcas restauraran el cargo de justicia o capitán. Se trataba de una figura de carácter extraordinario, nombrado de forma eventual en épocas de especial conflictividad, con competencias militares y judiciales superpuestas a las de los oficiales locales. Todo ello con el fin de asegurar el control del soberano sobre la élite local que dominaba los resortes del poder municipal (Iranzo, 2019: 371-372; Latorre, 2014: 266-269). Además, en el caso turolense, el justiciazgo solía compaginarse con la sobrejuntería, lo cual otorgaba a este individuo atribuciones ejecutivas y un contingente armado para mantener la paz y apresar a los delincuentes, lo que le reportaba una autoridad poco habitual en otras partes del reino (Ríos, 2016a: 287).

Durante estos momentos excepcionales de supresión de la normalidad concejil, los monarcas aprovecharon la presencia del justicia para disponer de las escribanías del concejo. Es el caso de Alfonso IV, quien en 1328 se dirigió al justicia de Teruel para que pusiera a disposición de Domingo de Aliaga el cargo de escribano de la escribanía de la villa. ${ }^{31}$ Por otro lado, este oficial real poseía su propia escribanía, en la cual los soberanos acomodaban a sus fieles

29 Dizen los de Teruel et de sus aldeas usasen et fuessen en possesion de las scrivanias et el senor rey aquellas contra lur voluntat se aya presas, demandan en possesion de las sobredichas seyer tornados (Gargallo, 2005: 204)

30 AHPTE, Concejo, caja 27, doc. 62, f. 1v.

31 ACA, Cancillería, registros, n. ${ }^{\circ} 531$, f. $4 \mathrm{v}$. 
a voluntad. ${ }^{32}$ Más allá fue Pedro IV, ya que entre 1355 y 1356 entregó a Domingo Jiménez de Lidón las escribanías del justicia y sobrejuntero, además de la de las aljamas de sarracenos y judíos. ${ }^{33}$ Nombramientos que no eran bien recibidos por las gentes de Teruel y, en más de una ocasión, se opusieron a que las personas designadas ejercieran su cargo. ${ }^{34}$

No obstante, durante los periodos en los cuales la universidad de Teruel gozaba de mayores cotas de autogobierno, la forma de actuar de la corona fue distinta. El primer ejemplo de este proceder lo protagonizó Juan I, quien mediante una carta rogatoria dirigida al concejo turolense solicitó que entregasen la escribanía del juez a Martín Serrano, escribano suyo. La petición le fue denegada, ya que las gentes de Teruel entendieron que ese proceder era contrario a las libertades y privilegios de la ciudad. ${ }^{35}$

Tras el Compromiso de Caspe, que supuso la llegada de una nueva dinastía al trono aragonés, la prerrogativa del concejo turolense de nombrar a su escribano podía haber pasado a manos reales. El origen de esta posible alienación se encontraba en la decisión tomada por los expertos en derecho comisionados para indagar sobre las rentas y derechos reales. Recién llegado al trono, Fernando I encargó a Francisco Sarzuela y a Juan de Sobirás, sacristán de la Seo de Zaragoza, realizar la citada investigación. Estos expusieron sus resultados durante las cortes generales celebradas en Zaragoza, donde determinaron que la escribanía turolense pertenecía al patrimonio real. Sin embargo, esta decisión fue contestada por los procuradores turolenses, quienes alegaron que el citado derecho era propiedad del concejo desde el privilegio firmado por Pedro III y el infante Alfonso en 1283. Este argumento convenció a los investigadores reales y reconocieron que el dito senyor rey don Ferrando no haver derecho alguno enla dita scrivania, mas aquella seyer cosa propria dela dita ciudat e poder fazer de aquella a su propria voluntat. ${ }^{36}$

Aclaradas las atribuciones de la ciudad respecto a esta institución municipal, los monarcas no volvieron a intentar enajenarla. Ahora bien, ello no sig-

Conservamos diferentes ejemplos relativos a varios reyes como Jaime II (ACA, Cancillería, cartas reales, Jaime II, caja 62, n. ${ }^{\circ}$ 7651), Alfonso IV (ACA, Cancillería, pergaminos, Alfonso IV, carp. 228, n. ${ }^{\circ} 671$ ) o Pedro IV (ACA, Cancillería, reg. 966, f. 2r.)

33 ACA, Cancillería, Cartas reales, Pedro IV, caja 45, n. ${ }^{\circ} 5605$.

34 Sobre este hecho nos ilustran las quejan elevadas al monarca por Domingo Jiménez de Lidón en 1356 (ACA, Cancillería, Cartas reales, Pedro IV, caja 45, n. ${ }^{\circ}$ 5605) o por Fernando Didac de Altarriba en 1357 (ACA, Cancillería, Registros, n. ${ }^{\circ}$ 966, ff. 56v-57).

35 AHPTE, Concejo, caja 27, doc. 62, f. 2v.

36 AHPTE, Concejo, caja 27, doc. 62, f. 2v. 
nifica que no intentasen influir en los nombramientos, lo cual hicieron siguiendo el ejemplo marcado por Juan I. El caso mejor conocido, debido a toda la documentación que generó, ocurrió durante los primeros años del reinado de Alfonso V; sin embargo, en esta ocasión no fue él sino la reina quien se dirigió a los magistrados turolenses. Concretamente el 4 de noviembre de 1420 la reina María firmaba una misiva destinada al juez, alcaldes, juez padrón, regidores y a toda la universidad de la ciudad de Teruel, en la cual les rogaba que encomendaran la escribanía de los tribunales de justicia locales al notario Gil de Torres, natural de Teruel. ${ }^{37}$

La petición real no fue respondida de inmediato, puesto que su lectura generó una discusión acerca de si su aceptación atentaba contra las libertades y privilegios de la ciudad. La deliberación dio comienzo a un largo proceso del cual tenemos noticias gracias a las descripciones que del mismo hicieron las partes implicadas: los regidores del municipio y Gil de Torres. ${ }^{38}$ Si bien ambas versiones coinciden en la gran mayoría de los puntos especificados, difieren sutilmente en algunos aspectos concretos, tal y como tendremos oportunidad de ver.

El primer paso dado por los magistrados locales ante el debate suscitado fue consultar a cuatro juristas pensionados por la ciudad, Jaime Martínez, Pedro Sánchez de Torres, Juan Agustín y Juan Sánchez de Orihuela. En torno a la decisión tomada por estos jurisconsultos encontramos la primera desavenencia entre las fuentes, puesto que la versión de Gil Torres indica que todos los letrados declararon no encontrar contrafuero en la petición, mientras que en la versión de los regidores los expertos no alcanzaron un acuerdo.

Sea como fuere, varios miembros del consejo echaron más leña al fuego al asegurar que, si bien la petición podía no ser contraria a los privilegios de la ciudad, entregar el puesto a Gil de Torres sí perjudicaba directamente al brazo de los caballeros ${ }^{39}$ La solución en este caso pasó por convocar a los caballeros quienes, junto a los regidores, debían reunirse y determinar si satisfacer la petición real era nocivo para sus intereses. El cónclave se celebró el 3 de enero de

37 AHPTE, Concejo, caja 27, doc. 20.

38 AHPTE, Concejo, caja 27, docs. 66 y 77 respectivamente.

39 No resulta extraño que el consejo únicamente defendiera los intereses del estrato social superior puesto que, al contrario que el concejo al que sustituyó en diversas funciones desde el siglo XIII, estaba compuesto únicamente por caballeros villanos. Monopolio indiscutido aun cuando Alfonso IV concedió a los menestrales y agricultores que pudieran elegir a dos o tres personas para que asistiesen a sus reuniones, quienes no debían ser estorbados ni impedida su asistencia (Ríos, 2016a: 288-289). 
1421 en la iglesia de San Miguel, sede de la cofradía de caballeros de San Jorge a la cual pertenecían los individuos de los principales linajes de la caballería villana (Ríos, 2016b: 125-126). Sin embargo, los miembros de la mano mayor se lavaron las manos y, argumentando que la epístola real iba dirigida primerament a judez, alcaldes, padron et regidores dela dita ciudat, pero subsiguientment se drezaba ala universidat dela dita ciudat ${ }^{40}$ y teniendo en cuenta la máxima latina quod omnes tangit ab omnibus debet expedito, ${ }^{41}$ resolvieron que se trataba de un asunto que debía ser considerado en un concejo general.

De ahí que en la sesión general del concejo celebrada el siguiente domingo se volviera a plantear esta cuestión. Con todo, el asunto continuó sin respuesta, ya que la decisión del conjunto de vecinos fue la de delegar la resolución del problema en los magistrados principales - juez, alcaldes, juez padrón y regidores - más veinte hombres de la mano mayor que habrían de ser elegidos por los regidores..$^{42}$ No conocemos el criterio que siguieron los regidores para hacer su elección, ni la nómina completa de los elegidos, pero aquellos de quienes sí ha llegado hasta nosotros su nombre pertenecían a los principales linajes de la oligarquía urbana. ${ }^{43}$ Asimismo, sabemos por las protestas elevadas por Gil de Torres que algunos de ellos se hallaban ausentes de la ciudad, lo cual estaba alargando el proceso, según él, de forma injustificada. ${ }^{44}$

Parece que el afectado tenía cierta razón en sus quejas, puesto que durante ese enero de 1421 el consejo y los veinte electos se reunieron en varias ocasiones, pero sin poder llegar al quorum necesario para una votación válida. Los regidores, por otro lado, negaban que la demora se hiciera con mala fe y aducían que, a pesar de la ausencia de la ciudad de algunos de los votantes, estos habían hecho llegar al consejo sus opiniones por escrito. Se trataba sin duda de Martín Martínez de Marcilla y de Pedro Garcés de Marcilla, cuyos votos realizados ante notario todavía se conservan. El primero de ellos, mediante

40 AHPTE, Concejo, caja 27, doc. 66, f. 1r.

41 AHPTE, Concejo, caja 27, doc. 66, f. 1r. Este aforismo proveniente del derecho romano sustentaba una cultura política basada en la noción de representación y se usaba para apoyar la intervención de todos los interesados de un cuerpo colectivo en materias que le empecían (Merello, 2005: 163-170).

42 Esto hacía que la decisión recayera sobre un total de 33 personas: los 20 caballeros elegidos por los regidores, los 7 regidores, los 4 alcaldes, el juez y el juez padrón.

43 Entre ellos se encuentran importantes personajes del Teruel del Cuatrocientos como: Martín Martínez de Marcilla, Pedro Garcés de Marcilla, Juan de Sadornil, Nicolás Palaciano, Domingo del Mesado, Berenguer de Besanta, Juan Martínez Donza, Francisco Domínguez del Mesado y Antón de España (AHPTE, Concejo, caja 27, docs. 60 y 61).

44 AHPTE, Concejo, caja 27, doc. 66, f. 1v. 
una carta fechada el 21 de enero de ese año, daba su consentimiento a la entrega de la escribanía a Gil de Torres ya que, en su opinión, por contemplation dela senyora reyna deven seyer hobedecidas las ditas sus pregarias. ${ }^{45} \mathrm{En}$ cambio, Pedro Garcés de Marcilla tenía un sentir radicalmente contrario; opinión a la que se adhirieron otros catorce de sus compañeros añadiendo sus rúbricas en el anverso del voto en sucesivos días. ${ }^{46}$

Además, Pedro Garcés redactó un pliego en el que exponía de forma pormenorizada las causas que le llevaban a negar la petición a la reina ${ }^{47}$ Este notario turolense iniciaba su exposición explicando lo perjudicial que era para las ciudades la costumbre real de realizar este tipo de concesiones, puesto que era la ciudad quien debía acarrear con los gastos, mientras que la corona no da res de sus cofres. A ello le seguían nueve ítems en los cuales daba una serie de razonamientos jurídicos que avalaban su voto negativo.

En primer lugar, indicaba que entregar el puesto a Gil de Torres significaría una pérdida de la capacidad de autogobierno de la urbe. Consecuencia derivada de acceder a un hecho directamente contrario a las ordenanzas municipales, las cuales dictaban que

[...] los regidores de aquella han acostumbrado e pueden poner e dar scrivanos en cadaun anyo alos ditos judez, alcaldes e jutge del padron e a regir la scrivania delas cortes de aquellos ab beneplacitum aquellos e por aquel tiempo que alos ditos regidores es o será bien visto. ${ }^{48}$

A continuación, presentaba la idea de que ceder a los deseos reales en este caso concreto podría sentar precedente y que, tras la defunción o destitución de Gil de Torres, los monarcas solicitaran escoger a su sucesor. Eventualidad que podrían presentar los sucesivos reyes como antecedente que justificara su preponderancia sobre la escribanía turolense, lo que resultaría en su enajenación perpetua. Además, con el fin de ilustrar mejor su teoría, incluía el ejemplo de donaciones que la ciudad realizó graciosamente a los soberanos anteriores, las cuales se habían convertido en pagos ordinarios.

Por otro lado, el autor aventuraba que, a pesar de la afectuosidad y el vocabulario usado por la reina en su misiva, en realidad no se trataba de una súpli-

45 AHPTE, Concejo, caja 27, doc. 60.

46 AHPTE, Concejo, caja 27, doc. 61.

47 AHPTE, Concejo, caja 27, doc. 62.

48 AHPTE, Concejo, caja 27, doc. 62, f. 1r. 
ca sino de una orden, lo cual implicaba contrafuero. Este argumento se sustenta en la forma de actuar del propio Gil de Torres en sus reuniones con el concejo turolense, así como las palabras con que este se dirigió a los magistrados locales. ${ }^{49}$ Lo que Pedro Garcés conseguía con ello era desnudar al texto real de las exigencias teatrales que generalmente revisten a las relaciones de dominación, discurso público - public transcript - a través del cual el poder busca crear la apariencia que da de sí mismo. Para ello se basaba en la actuación del enviado regio ante el consejo turolense ya que, olvidado el código formal imperante en estas relaciones, este expuso el discurso oculto - hidden transcript - que se escondía tras la solicitud real al mencionarles que se trataba de una orden y no una petición (Scott, 2000: 24-37). El abandono por parte de Gil de Torres del uso de las fórmulas y retórica que marcaban el juego político entre estos dos poderes, monarquía y concejo, y la exposición clara de las intenciones monárquicas sirvió al delegado concejil como otro argumento para negar la cesión de la escribanía.

Otra de las causas alegadas por Pedro Garcés para no atender a la súplica real era el perjuicio que ello conllevaba para los futuros jueces y jueces del padrón. El daño, en este caso, radicaba en que, si la ciudad no elegía al notario para el citado oficio público, ellos podían elegir libremente. De donde resultaba que el puesto solía recaer cada año en una persona cercana a los magistrados principales. Asimismo, de lo que se desprende de este epígrafe, se puede deducir que varios notarios turolenses se turnaron en el cargo, consiguiendo beneficiarse todos de él. Situación que, según este delegado, era preferible ya que es mas razonable cosa que muchos se abtifiquen et se sostengan potisime (sic) del officio publico e dela cosa publica que uno solo. ${ }^{50}$

Tras estos pretextos de carácter más general, Pedro Garcés de Marcilla cargaba las tintas contra el propio Gil de Torres al indicar que varias personas sospechaban de su deshonestidad. Lo que es más, aducía que varios miembros del concejo habían manifestado que preferirían renunciar al cargo de juez antes que ejercerlo con un individuo como Gil de Torres al frente de su escribanía.

Puntos, estos dos últimos, que no solo nos hablan de un sistema de turnos establecido por un conjunto de la oligarquía para sacar rédito personal de los

Que las ditas pregarias sean o puedan seyer mandamiento puede se inferir del decir e cominaciones quel dito Gil de Torres ha fecho en la sala de la dita ciudat razonando de la present materia e demandando respuesta. AHPTE, Concejo, caja 27, doc. 62, f. 1v.

50 AHPTE, Concejo, caja 27, doc. 62, f. 2r. 
oficios públicos. Sino que también permiten observar la imposibilidad de aquellos carentes de capital relacional ${ }^{51}$ en la localidad para entrar en los engranajes de la administración municipal, aun cuando gozaran del favor regio, como ocurrió con Gil de Torres.

Finalmente, abandonaba los argumentos subjetivos y recurría a otros más formales para justificar su decisión, concretamente a la jurisprudencia. Con ese fin utilizó sentencias favorables al concejo en casos similares, entre las que se cuentan las resoluciones emitidas cuando Juan I y más tarde Fernando I intentaron apropiarse de la escribanía turolense, ambas comentadas anteriormente.

El Marcilla concluía su disertación infiriendo que, por estas razones, amén de otras en pro de la utilidad de la cosa pública que no se detuvo en explicar, el concejo de Teruel no se debía plegar a la petición de la corona. Sin embargo, parece que este alegato no sirvió para convencer a todos los miembros de la junta encargada de tomar la decisión, puesto que ese mismo día Gil de Torres se personó en la sala del concejo y presentó un requerimiento formal con intención de acelerar el proceso. ${ }^{52}$ Mediante esta demanda el afectado exponía que habían pasado tres meses desde la recepción por parte del concejo turolense de la misiva de la reina, y que todavía no había obtenido respuesta. Tardanza que le estaba perjudicando en gran manera y que achacaba a la mala fe de algunos magistrados quienes, según él, retrasaban la elección a propósito. Por todo ello, Gil de Torres conminaba a los oficiales del consejo y a los veinte electos a reunirse y tomar una decisión, la cual debían transmitir a la soberana.

La exhortación de Gil no fue bien recibida por el cuerpo de regidores, ya que tres días después, el 30 de enero, uno de los aludidos, Pedro Sánchez de Torres, le envió una respuesta. En ella argumentaba que los veinte caballeros electos todavía no habían emitido su voto y, hasta no saber de su opinión, los regidores no podían pronunciarse. ${ }^{53} \mathrm{Al}$ poco tiempo, el resto de regidores redactaron otra respuesta más extensa que la de Pedro Sánchez de Torres, en ella

51 Entiéndase el capital relacional como la suma de relaciones que una persona es capaz de movilizar dentro de la red social en la cual se halla inserto y de la que participa. En este sentido, no es tan determinante el capital propio como la posición de un individuo en la red y la capacidad de movilización de recursos de aquellos con los que está relacionado. Para comprender mejor este concepto consultar las obras de José María Imízcoz y Alicia Montero (Imízcoz, 2010: 227-282; Montero, 2018: 230-231).

52 AHPTE, Concejo, caja 27, doc. 77.

53 AHPTE, Concejo, caja 27, doc. 63. 
explicaban todo el proceso seguido desde la lectura de la súplica real hasta ese momento. ${ }^{54}$ También se hacían eco de los votos emitidos por algunos de los delegados, en especial de la disertación de Pedro Garcés de Marcilla, y excusaban a los que todavía no habían manifestado su dictamen por no estar presentes en la ciudad, si bien los regidores se comprometían a enviar recaderos para convocarlos a una nueva reunión.

Simultáneamente, advertían que si bien la dita ciudat ha et tiene otros negocios et cosas mas arduas et mas ponderosas et concernientes mayor provecho o mayor dampnage dela cosa publica, los regidores habían tratado el caso de Gil de Torres con diligencia y habían atendido a este las siete veces que había acudido a la sala del consejo reclamando audiencia. Además, argumentaban que el retraso no podía perjudicar al protegido de la reina y a sus negocios, ya que en lo que se demanda gracioso si no se da no es fecho prejudicio al demandant, nin se le sigue dampnage, ni perdua (sic) de expensas, greuges et menoscabos, de donde inferían que si había algún daño, este era producido por la desatención que el propio Gil de Torres mostraba hacia su casa y negocios. Por todo ello negaban las acusaciones de actuar de mala fe, y reiteraban su incapacidad de acción hasta no tener conocimiento de la opinión de los veinte comisionados elegidos.

A tenor de la documentación conservada, parece ser que las deliberaciones se prolongaron durante un mes más. No fue hasta el 20 de febrero de 1421 cuando los regidores turolenses enviaron una carta con su respuesta a la reina María, en la cual explicaban el proceso seguido y la resolución final de los turolenses encargados de decidir sobre el asunto. Estos, a pesar de la súplica de la monarca y de su recomendación avalando al citado Gil, habían determinado que atentaba contra las libertades y privilegios de la ciudad y, en consecuencia, debían negar la entrega de la escribanía a Gil de Torres. ${ }^{55}$

El perjudicado no aceptó la sentencia y, basándose en la existencia de varios votos favorables a su candidatura, decidió iniciar un pleito contra la ciudad. Con ese fin reclamó al concejo turolense copia del acta de votos, petición que también le fue denegada. ${ }^{56}$ A pesar de este contratiempo, Gil de Torres llevó a la ciudad ante la justicia real, si bien la presentación del privilegio otorgado por Pedro III a Teruel en 1283 hizo que se ratificara la autonomía del 
concejo para decidir sobre la materia. No obstante, Gil de Torres no se dio por vencido y el 29 de marzo de ese mismo año nombró a García de Fombuena, notario y vecino de Teruel, procurador suyo, con intención de que este lo representase en el pleito contra la ciudad. Este letrado, mejor conocedor de las leyes locales que Gil de Torres, pedía la nulidad de la sentencia basándose en que, según el fuero de Teruel, los habitantes del lugar únicamente podían ser juzgados en los tribunales de la ciudad. ${ }^{57}$ Desgraciadamente no se ha conservado más documentación referente a este asunto, por lo que no sabemos si la demanda siguió adelante ni su resolución.

En cualquier caso, todos estos ejemplos demuestran que poseer estas escribanías concejiles, aun cuando ya estaban desligadas de la magistratura concejil originaria, reportaba importantes beneficios. Ello explica los constantes intentos de la monarquía por colocar en ellas a gentes de su entorno, así como la férrea defensa que de su posesión hacía el concejo de Teruel.

\section{Consideraciones finales}

Tal y como se ha anticipado al comienzo de este trabajo, lo que se ha pretendido a lo largo de estas páginas ha sido analizar la escribanía del concejo de Teruel durante la Baja Edad Media. El origen de esta institución se remonta, al igual que en otras villas de la Extremadura, al momento de creación del propio concejo, con el fin de cubrir las necesidades de la nueva administración local. Para su creación se tomó como modelo el existente en la cercana villa de Daroca, por lo que en sus primeros momentos compartieron gran número de características como su elección por el concejo o la periodicidad anual. Igualmente, este organismo fue monopolizado por los caballeros villanos que conformaron la oligarquía local, lo cual se debió a los requisitos de acceso. Si bien la obligación de que sus ocupantes fueran letrados hizo que el puesto recayera en clérigos durante la primera etapa, muestra de las necesidades técnicas necesarias para el buen funcionamiento del aparato administrativo municipal.

Sin embargo, parece que desde su origen el escribano del concejo turolense tuvo más atribuciones que las de sus homólogos de concejos vecinos. A las labores de redacción de toda la documentación emanada de este órgano gubernativo y de fedatario concejil se sumaban distintas labores fiscales 
y contables. Pero, además, su posición como auxiliar del juez hacía que también tuviera tareas en el ámbito judicial, donde no solo se encargaba de labores burocráticas, sino que era parte indispensable en los tribunales de apelación.

Ahora bien, no nos encontramos ante un organismo estático, sino que evolucionó y cambió a lo largo del tiempo. En este sentido, durante el siglo XIII absorbió competencias jurídico-fiscales que en origen eran propias de otros magistrados como el juez o los alcaldes. El campo en el que más aumentaron sus atribuciones fue, sin duda, el judicial ya que, por su labor de intérprete de los fueros — libro padrón - , llegó a monopolizar el tribunal de apelación a las sentencias emitidas por el juez en primera instancia. Hecho por el cual este funcionario también pasó a ser denominado como juez padrón.

Por otro lado, al menos desde finales de la decimocuarta centuria, parece que la escribanía del concejo de desdobló en dos oficinas separadas con notarios diferentes, si bien a la cabeza de ambas seguía estando el escribano del concejo elegido anualmente. Una de ellas estaba dedicada a las tareas propias de la administración concejil, entre las que se encontraba la realización de todos los documentos dimanados de la gestión y gobierno municipal; mientras que la otra se encargaba de la elaboración de los registros originados en los tribunales del juez, alcaldes y juez padrón.

Otro de los temas abordados han sido los cuantiosos beneficios, tanto individuales como colectivos, derivados de la posesión de esta magistratura o de un puesto de notario en estas escribanías, y los enfrentamientos entre el concejo y la monarquía por tener la autoridad de decidir qué individuo ocupaba el puesto. Prebenda que desde 1283, gracias al privilegio otorgado por Pedro III, tenía el concejo, que controló qué notarios trabajaban en las escribanías del concejo y del juez, además de decidir por cuánto tiempo lo hacían. Esta eventualidad se tradujo en la ocupación de estos oficios por parte de un pequeño grupo de notarios turolenses cercanos a la élite que se turnaban en los mismos, con la consecuente exclusión de otros profesionales escriturarios como Gil de Torres. Personaje que, a pesar de ser vecino de la ciudad y contar con el apoyo expreso de la monarquía, no poseía el suficiente capital relacional dentro de la localidad. Circunstancia que le imposibilitó entrar a formar parte del grupúsculo de personas que monopolizaron los puestos administrativo-gubernamentales del municipio y se lucraron con su disfrute. 


\section{Referencias bibliográficas}

Agudo Romeo, María del Mar (1992), El fuero de Daroca. Introducción, edición crítica, traducción, estudio léxico y concordancia. Daroca, Centro de Estudios Darocenses.

Agudo Romeo, María del Mar, Ana Isabel LAPEÑa PAúl y María Luz RodRigo ESTEVAN (2007), «Las fuentes: manuscritos y ediciones de los fueros de Teruel y Albarracín.» En Guillermo Redondo Veintemillas y Esteban Sarasa Sánchez, eds., Tiempo de Derecho foral en el sur aragonés: Los fueros de Teruel y Albarracín. Zaragoza, El Justicia de Aragón: 281-360.

APARICI MARTí, Joaquín (2011a), «De domo dicti domini comitis. Aproximación a la corte señorial de don Federico de Aragón, conde de Luna (1420-1425)», Aragón en la Edad Media, 22: 19-48.

APARICI MARTí, Joaquín (2011b), «Judíos de Belchite en el denominado 'libro de escribanía' de Federico de Aragón, conde de Luna (14221425)», Sefarad, 71/1: 2549.

APARICI MARTí, Joaquín (2013), «Federico, conde de Luna, candidato desestimado al trono de la Corona de Aragón: Su 'libro de escribanía' (1420-1425).» En María Isabel Falcón Pérez (coord.), El compromiso de Caspe (1412), cambios dinásticos y Constitucionalismo en la Corona de Aragón. Zaragoza, Ibercaja-Diputación General de Aragón: 189-200.

BARRIO BARRIO, Juan Antonio (2011), «'Per Servey de la Corona d’Aragó.’ Identidad urbana y discurso político en la frontera meridional del reino de Valencia: Orihuela en la Corona de Aragón, ss. XIII-XV», Hispania: Revista española de historia, 71/238: 437-466.

CARUANA GÓMEZ DE BARREDA, Jaime (1971), «El poder real y su intervencionismo en las luchas fratricidas de Teruel hasta el año 1500», Teruel, 45-46: 241-308.

CASTÁN ESTEBAN, José Luis (2008), «El sistema judicial en Teruel y su comunidad en el siglo XVI». En Ricardo Franch Benavent y Rafael Benítez Sánchez-Blanco, coords., Estudios de historia moderna en homenaje a la profesora Emilia Salvador Esteban. Valencia, Universidad de Valencia: 115-134.

CASTÁn ESTEBAn, José Luis (2009), El final de los fueros de Teruel y Albarracín en el siglo XVI. Teruel, Centro de Estudios de la Comunidad de Albarracín.

Castán Esteban, José Luis (2010), Suma de los fueros de las ciudades de Santa María de Albarracín y de Teruel, de las Comunidades de Aldeas de dichas ciudades y de la villa de Mosqueruela y de otras villas convecinas. Teruel, Instituto de Estudios Turolenses.

CASTAÑé LlinÁs, José (1989), El fuero de Teruel. Edición crítica con introducción y traducción. Teruel, Ayuntamiento de Teruel.

Conde Y DElGado DE MolinA, Rafael (1989), «Notarías y escribanías de concesión real en la Corona de Aragón (siglo XIII).» En José Trench Odena, ed., Notariado 
público y documento privado: de los orígenes al siglo XV. Actas del VII Congreso Internacional de Diplomática. Volumen 1. Valencia, Generalitat Valenciana: 281-331. CORRAL GARCíA, Esteban (1987), El escribano de concejo en la Corona de Castilla (siglos XI al XVII). Burgos, Ayuntamiento de Burgos.

DíEZ SÁNCHEZ, Marta (1998-1999), «La escribanía de la sala del Consell: un oficio controvertido», Revista de Historia Moderna, 17: 311-320.

FALCÓN PÉREZ, María Isabel (1997), «La regulación del notariado oscense en el siglo XIV», Studium, 3/1: 135-150.

GARCíA DíAZ, Isabel (2015), «De escribano de concejo a escribano mayor. La formación de las cancillerías urbanas.» En Pilar Pueyo Colominna, coord., Lugares de escritura: la ciudad. Zaragoza, Institución Fernando El Católico: 285-300.

Gargallo Moya, Antonio (1996), El concejo de Teruel en la Edad Media, 1177 1327. Teruel, Instituto de Estudios Turolenses.

Gargallo Moya, Antonio (2005), El concejo de Teruel en la Edad Media, 11771327. Vol. IV. Documentos. Teruel, Instituto de Estudios Turolenses.

Gomariz MARín, Antonio (2003-2004), «Las escribanías en la ciudad de Murcia a fines de la Edad Media», Miscelánea Medieval Murciana, 27-28: 35-67.

IMÍzCOZ BEUNZA, José María (2010), «El capital relacional. Relaciones privilegiadas y redes de influencia en el Estado español del siglo XVIII.» En José María Imízcoz Beunza y Oihane Oliveri Korta, eds., Economía doméstica y redes sociales en el Antiguo Régimen. Madrid, Sílex: 227-282.

IRANZO MuÑío, María Teresa (2004), El concejo de Huesca en la Edad Media: estructura, funcionamiento y financiación de la organización municipal en la Baja Edad Media, Universidad de Zaragoza. Disponible en red: https://zaguan.unizar. es/record/56342/files/TESIS-2016-167.pdf

IRANZO MuÑío, María Teresa (2019), «Los capitanes Cerdán de Escatrón, agentes del estado en las comunidades del sur de Aragón (1440-1500).» En Concepción Villanueva Morte y Mario Lafuente Gómez, coords., Los agentes del Estado: poderes públicos y dominación social en Aragón (siglos XIV-XV). Madrid, Sílex: 363-395.

JARA FUENTE, José Antonio (2001), «Élites urbanas y sistemas concejiles. Una propuesta teórico-metodológica para el análisis de los subsistemas de poder en los concejos castellanos de la Baja Edad Media», Hispania: Revista española de historia, 61/207: 221-266.

LADERo QueSADA, Miguel Ángel y GALÁN PARRA, Isabel (1982), «Las ordenanzas locales en la Corona de Castilla como fuente histórica y fuente de investigación (siglos XIII al XVIII)», Anales de la Universidad de Alicante. Historia Medieval, 1: 221-244.

LATORRE CIRIA, José Manuel y PÉREZ PÉREZ, Isabel, (2006), El gobierno de la ciudad de Teruel en el siglo XVII. Zaragoza, Prensas Universitarias de Zaragoza.

LATORRE CIRIA, José Manuel (2014), «La ciudad en la Edad Moderna.» En Montserrat Martínez González y José Manuel Latorre Ciria, coords., Historia de la ciudad de Teruel. Teruel, Instituto de Estudios Turolenses: 251-293. 
LE GoFf, Jacques (1991), El orden de la memoria. Barcelona, Paidós.

LETHONEN, Tuomas (2007), «Préliminaires. Colonisation et culture écrite : les sources du pouvoir des élites au nord de la mer Baltique». En Tuomas Lethonen y Elisabeth Mornet, coords., Les élites nordiques de l'Europe occidentale (XII-XV siècle). París, Publications de la Sorbonne: 11-19.

LEVA CUEvas, Josefa (2009), «Escribanos y notarios en la Castilla bajomedieval. Su ejercicio en la Córdoba de la época», Ámbitos, 21: 63-94.

MEREllo ARECCO, Italo (2005). «La máxima "Quod omnes tangit”: Una aproximación al estado del tema», Revista de estudios histórico-jurídicos, 27: 163-175

MonTERo MÁlagA, Alicia (2018), «Capital relacional y capital social en el acceso de la alta nobleza al gobierno municipal burgalés a principios del siglo XVI: la provisión de la alcaldía mayor a Francisco de Brizuela», En la España Medieval, 41: 227-256.

MuÑOZ GARRIDO, Vidal (2007), Teruel. De sus orígenes medievales a la pérdida del fuero en 1598. Zaragoza, INO-Reproducciones.

OlIVARES TEROL, Ana Ángeles (1995), «La escribanía concejil jumillana en el XVI», Murgetana, 91: 17-31.

PARDO RoDRíGUEZ, María Luisa (2000), «La escribanía mayor del concejo de Sevilla en la Edad Media». En Walter Prevenier y Thérèse de Hemptinne, La diplomatique urbaine en Europe au Moyen Âge. Actes du congrès de la Commission internationale de diplomatique. Leuven, Garant: 356-380.

PUÑAL FERnÁNDEZ, Tomás (2019), «Escribir al rey: la comunicación de las ciudades realengas de la meseta castellana con la Corona en la Baja Edad Media», Documenta \& Instrumenta, 17: 127-145.

RÁBADE OBRAdó, María Pilar (1991), «Las escribanías como conflicto entre poder regio y poder concejil en la Castilla del siglo XV: el caso de Cuenca», Anuario de Estudios Medievales, 21: 247-276.

RÁBADE OBRADÓ, María Pilar (1992), «Las lugartenencias de escribanías como conflicto: un ejemplo de la época de los Reyes Católicos», Espacio, Tiempo y Forma. Serie III Historia Medieval, 5: 211-228.

Ríos CONEJERO, Alejandro (2016a), «El poder de la oligarquía urbana de Teruel durante la Baja Edad Media», Aragón en la Edad Media, 27: 271-297.

Ríos CONEJERO, Alejandro (2016b), «Los caballeros villanos de Teruel. Un acercamiento a la identidad del grupo y su cultura en la Baja Edad Media.» En Paulino Iradiel et al., Identidades urbanas Corona de Aragón-Italia. Redes económicas, estructuras institucionales, funciones políticas (siglos XIV-XV), Zaragoza, Prensas de la Universidad de Zaragoza: 115-130.

RODRÍGUEZ LLOPIS, Miguel (1988), «La escritura y el poder. La emisión de documentos en la sociedad murciana bajomedieval», Áreas: Revista internacional de Ciencias Sociales, 9: 11-24.

RUIZ PILARES, Enrique José (2018), «Los escribanos mayores de los concejos castellanos en el siglo XV: una élite de burócratas al servicio del grupo dirigente. Los 
Román de Jerez de la Frontera», Bajo Guadalquivir y Mundos Atlánticos, 1: 193210 .

SCOTT, James (2000), Los dominados y el arte de la resistencia. Discursos ocultos, Buenos Aires, Ediciones Era.

TORRES SANZ, David (1982), La administración central castellana en la Baja Edad Media. Valladolid, Universidad de Valladolid. 